\title{
约 \\ DISSERTAÇÕES DE MESTRADO DEFENDIDAS EM 2020 NO MESTRADO PROFISSIONAL EM PODER LEGISLATIVO
}

Fernandes, Lília Ribeiro. A descentralização administrativa no Poder legislativo [manuscrito] / Lília Ribeiro Fernandes. 2020.91f.

Orientador: Prof. Dr. Nelson Gomes dos Santos Filho

Resumo: Ao longo das últimas décadas, a estrutura organizacional da Câmara dos Deputados (CD) cresceu e se diversificou significativamente, mas sua gestão permaneceu centralizada, exigindo maior esforço de planejamento e alocação de recursos para atividades bem distintas - indo das atribuições propriamente legiferantes a atividades-meio como a gestão de tecnologia da informaçãoe a gestão hospitalar. O emprego do instituto da descentralização administrativa poderia ser um caminho para redução desse esforço e melhoria da eficiência. Este trabalho se propôs, portanto, ao exame das possibilidades de aplicação do instituto da descentralização no âmbito das a tivida des administrativas da CD e, por não haver experiência prévia de utilização do instituto no âmbito do Poder Legislativo, escolheu-se analisar a experiência mais próxima que se teve disso, qual seja a autonomização de órgãos no âmbito do Sena do Federa 1(SF), optandose por um estudo qualitativo e descritivo da experiência prévia havida na Secretaria de Tecnologia da Informação do SF, o Prodasen, haja vista seu pioneirismo na aplicação da tecnologia da informação no Poder Legislativo ser comumente atribuído à autonomia que lhe era conferida. Como referencial teórico, analisou-se a descentralização administrativa no Brasil, sob a ótica da esfera federal, sustentando-se a constitucionalidade da sua adoção no âmbito do Poder Legislativo e delineando-se as atividades administrativas no âmbito da CD que seriam passíveis de descentralização. Abordou-se o histórico da reforma gerencial no Brasil, destacando-se o uso do contrato de gestão para controle de desempenho de atividades descentralizadas, e, para a compreensão do componente político inerente a qualquer processo decisório no âmbito administrativo de uma ca sa legislativa, a colheu -se a ótica da teoria da escolha racional. Ao fim da pesquisa, foi possível concluir que a concessão de autonomia para o desempenh ode determinadas atividades contribui, de fato, para uma maior eficiência, sendo recomendável, todavia, que, em uma eventualdescentralização, haja uma definição prévia, via contrato de gestão, de metas e objetivos a serem cumpridos pelo ente descentralizado, garantindo-se uma coerência com a missão institucional do ente central.

Palavras-chave: Poder Legislativo. Descentra lização a dministrativa. Contra to de gestão. Teoria da Escolha Racional. Prodasen.

Rezende, Karluce Santos. Implantação da gestão da saúde e segurança do trabalho na Câmara dos Deputados: uma análise sob a ótica da mudança organizacional, 2020.101 f.

Orientador: Prof. Dr. Nelson Gomes dos Santos Filho

Resumo: O bem-estar no trabalho passa pela promoção da saúde e proteção da integrida de física dos trabalhadores e requer da organização um esforço para desenvolver um sistema que promova a gestão estrutura da dos a ssuntos rela cionados à saúde e segurança do trabalho (SST). Para as orga nizações públicas essa temática ainda é novidade atualmente. Dada a ausência de uma legislação específica no assunto que abranja toda a administração pública em seus diferentes Poderes e esferas - federal, estadual, distrital e municipal - o que se observa é um vácuo normativo que impacta no dia a dia dos servidores públicos estatutários. Há instituições que têm busca do implementar uma gestão da SST, sendo este o ca so da Câmara dos Deputados que estabeleceu um sistema precursor em 2005 que, em 2010, passou por mudanças, culminando em 2016 com o sistema vigente nos dias atuais. Este trabalho objetiva investigar esse processo de implantação da gestão da SST na Câmara dos Deputados. Trata -se de um estudo de caráter qualita tivo e descritivo que, a partir dos a chados na pesquisa documentale nas entrevistas semiestru turadas, procede-se à análise do processo de implantação da gestão atual da SST. Para tanto, toma-se como base a mudança orga niza cional ocorrida no período de 2010 e 2015, que culminou na impla ntação do novo sistema de gestão da SST em 2016. A teoria norteadora da análise é a abordagem de Kurt Lewin aplicada no contexto de mudanças organizaciona is que dita que, para se obter mudanças efetivas nas organizações, deve-se seguir 
três passos: descongelar o status quo; mover ou agir; "recongelar" no novo estado. Durante o processo deve-se considerar as forças envolvidas para então se planejare executar as ações para a mudança, sendo um processo cíclico e colaborativo. A a nálise é realizada mediante a identificação: das forças atuantes no primeiro momento, que se estende de 2005 a 2009; das ações tomadas no período de transição, 2010e 2015; e por fim, das forças vigentes no atualestá gio e das ações toma das para a estabilização nesse está gio, que vigora desde 2016 até 2019. Espera-se, a partir da compreensão do processo de implantação da gestão da SST na Câmara dos Deputados, colaborar com demais órgãos e instituições públicas no seu processo de estruturação da SST ou pelo menos despertaro interesse pelo tema.

Palavras-chave: Saúde e Segurança do Trabalho. Mudança Organizacional. Servidor Público. Gestão Pública. Câmara dos Deputados. Poder Legislativo.

Pomagerski Junior, Carlos Antônio. Análise comparativa entre as legislações adotadas nos Estados Unidos e Brasil referentes à defesa cibernética, $2020.98 \mathrm{f}$.

Prof. Dr. Cristiano Ferri Soares de Faria

Resumo: Foi realizado o estudo das legislações referentes à Defesa Cibernética nos Estados Unidos, juntamente com bibliografia sobre o tema, traçando-se um paralelo com o panorama legislativo Bra sileiro. A pesquisa foi desenvolvida por meio de revisão da literatura, sobre legislações relacionadas a defesa cibernética nos EUA e no Brasil, englobando livros, artigos, documentos oficiais, e corpo legislativo. O recorte legislativo se deu no normativo legal cogente, latu sensu, referentes às leis de defesa cibernética. Nos Estados Unidos foi utilizado o recorte para abranger apenas as leis federais que são determinações gerais a todo país. Dessa forma, como o pretendido, o presente trabalho após pesquisar bibliografia e legislações fez um estudo compara do com as legisla ções de cogência federal bra sileira s. Incluindo ta mbém as estruturas criadas por essas legislações. Traçou-se possíveis lacunas nos sistemas e com a comparação de ambos tentou-se sugerir possíveis melhoras, assim como mostrar que uma cooperação entre o Bra sil e os Estados Unidos seria benéfica a ambos países.

Palavras-chave: Defesa cibernética. Marco Civil da Internet. Poder legislativo.

Ceolin, Adriano Wilson. A transformação do PMDB dentro da liderança do partido na Constituinte: a perspectiva da história oral, $2020.309 \mathrm{f}$.

Orientador: Prof. Dr. Rildo José Cosson Mota

Resumo: O Partido do Movimento Democrático Brasileiro (PMDB) liderou o processo de aprovação da Constituição de 1988, e a o mesmo tempo sofreu efeitos cola tera is que, se m dúvida, impactam na existência da sigla a té os dias atuais. Quando se iniciaram os trabalhos da Assembleia Nacional Constituinte (ANC), a bancada do PMDB contava com 303 congressistas (deputados e senadores), o que lhe permitia exercer hegemonia política no processo de elaboração da nova Carta Ma gna. Não obstante, ao longo da votação do texto constitucional, divergências dentro da bancada do PMDB geraram embates e discussões que fragmentaram a sigla e a tra saram - qua se inviabilizando - a a provação da nova Constituição. Oápice desse processo aconteceu quando, em junho de 1988, antes do fim da promulgação do texto constitucional, dissidentes do PMDB fundaram o Partido da Social Democracia Brasileira (PSDB). A ação foi protagonizada pelo então líder do PMDB na Constituinte, senador Mário Covas (São Paulo), que foi acompanhado por seu primeiro vice-líder, deputado Euclides Scalco (Paraná). O objetivo geral deste trabalho é apresentar como se deu a transformação do PMDB dentro da Liderança do Partido na Constituinte. Para tanto, utilizar-se-á a metodologia de História Oral temática, que se ba seia em entrevistas de participantes do período que se busca a na lisar. A ela boração da serguntas das entrevistas foi subsidiada pela construção de contextos com base em documentos oficiais, reportagens e pesquisas bibliográficas relacionadas a o PMDB e à ANC. Neste trabalho, foram entrevistadas oito pessoas que atuaram na Liderança: cinco vice-líderes, duas funcionárias públicas e um assessor político. São eles: Euclides Scalco, Antônio Britto, Nelson Jobim, Cássio Cunha Lima e Rose de Freitas (vice-líderes); Susana Pereira e Julia Bulgarelli (funcionárias); e Marco Vinício Petrelluzzi (assessor político). Esta pesquisa concluiu que as ações da Liderança do PMDB na ANC impactaram nos rumos da sigla, cujo maior exemplo é seu desmembramento. Ta is ações se deram por conta das próprias características da sigla criada como frente, mas sobretudo por conta do choque entre grupos políticos que atua vam no PMDB a té então.

Palavras-chave: Poder Legislativo. Constituinte 1988. PMDB. Liderança do PMDB. História Oral 
temática.Partido político.

Cerqueira, Wanessa Gabrielle Maia. A política de drogas na Câmara dos Deputados: análise do discurso parlamentar, 2020.92f.

Orientador: Dr. Antonio Teixeira de Barros.

Resumo: Análise dos discursos parlamentares no debate sobre a nova Política Nacional de Drogas (Lei ${ }^{\circ}$ 13.840/19), que tramitou na Câmara dos Deputa dos, em relação à produção, comercia lização e consumo de substâncias psicoativas. O objetivo da pesquisa foi identificar as formações discursivas nas quais se ba seiam ta is discursos, para analisar a forças de poder que funda mentara m a discussões e compreender as crenças ideológicas que permeiam os posiciona mentos dos deputa dos. Assim, in vestiga mos como os parla mentares se posicionam acerca da temática drogas, em situações comunicativas que envolvem o debate parla mentar na Câmara dos Deputados, bem como as estratégias discursivas que são utilizadas para comunicar determina das visões em relação ao tema. Pa ra tanto, a nalisa mos as notas taquigráficas dos debates ocorridos na Comissão Especial destina da a deliberar sobre a proposição, bem como na discussão e votação da matéria no Plenário da Câmara dos Deputados. Foram identificadas, em ordem decrescente de intensidade, a existência de uma formação discursiva sanitarista, segundo a qual ao Estado cabe zelar e cuidar da saúde do indivíduo, ainda que contra sua própria vontade; de uma formação discursiva punitivista, que defende a necessidade de uma lei penal rígida para conter o consumo individual e o comércio de substâncias psicoativas; e uma formação discursiva libertária, identifica da em poucos pronunciamentos, que se baseia no respeito a o livre-arbítrio e na não interferência na vida íntima e privada do indivíduo.

Palavras-chave: Poder Legislativo. Discurso Político. Análise de Discurso. Política de Drogas.

Bijos, Paulo Roberto Simão. Orçamentação por desempenho no Congresso Nacional: incentivos institucionais e comportamento legislativo, 2020.306f.

Orientador: Prof. Dr. Nelson Gomes dos Santos Filho

Resumo: Esta dissertação trata da orçamentação por desempenho no âmbito do Congresso Nacional. O objetivo proposto foi o de identificar e a valiar, com abordagem descritiva e exploratória, os e spaços para o uso de informações de desempenho no processo legislativo orçamentário federal. Com amparo na teoria neoinstitucionalista, a pesquisa realizada valeu-se do método de estudo de caso, centrado na investigação sobre o uso de informações de desempenho pela Comissão Mista de Planos, Orçamentos Públicos e Fiscalização (CMO), no período de 2014 a 2020, com base em dois eixos estruturais de análise: o institucional, orientado a identificar e avaliar os incentivos institucionais a o uso dessas informações; e o comportamental, que buscou identificar e avaliar o próprio uso de informações de desempenho pelos parlamentares. É da teoria neoinstituciona lista, a final, a máxima de que as "instituições importam" para a compreensão do comportamento social. Como resultado, concluiu-se que, embora a CMO seja cercada de incentivos institucionais a o uso de informações de desempenho, as ocorrência s práticas de utilização dessas informações são muito escassas. Em face disso, foram apresentadas, ao final desta dissertação, algumas recomendações destinadas ao fortalecimento da orçamentação por desempenho no âmbito do Congresso Nacional, seguidas de reflexões doutrinárias pertinentes a o tema em estudo.

Palavras-chave: Comissão Mista de Planos, Orçamentos Públicos e Fiscalização. Congresso Nacional. Neoinstituciona lismo. Orçamentação por Desempenho. Orçamento Público. Poder Legislativo.

Almeida, Nata lia Gonçalves Beling de. O processo de gestão de riscos no Senado Federal: uma análise sobre o processo de implantação, 2020. $165 \mathrm{f}$.

Orientador: Prof. Dr. João Luiz Pereira Marciano

Resumo: O debate sobre governança corporativa e gestão de riscos a lcançou grande importância na esfera governamentalem razão da presença de relações de a gencia: o principal (a sociedade) delega ao agente (o Estado) a responsabilidade de gerir os recursos provenientes dos contribuintes. Nesse cenário, o desafio da governança e definir o quanto de incertezas deve ser aceito na gestão dos recursos públicos. A gestão de riscos e o instrumento a propria do para lidar com isso, uma vez que a mplia a ca pacida de da organiza ções de trataro efeito das incertezas sobre os objetivos organizacionais. Consequentemente, esse mecanismo permite a sorga nizações gerar va lor e entregar serviços de modo mais efetivo, eficiente e econômico. Assim, 
gerenciar a aplicação de recursos da sociedade com base em riscos e primordial, sendo também uma recomendação de entidades como a Organização para a Cooperação e Desenvolvimento Econômico (OCDE) e o Tribunal de Contas da União (TCU). Nesse contexto, a presente pesquisa buscou descrever o processo de implantação da gestão de riscos no Sena do Federala luz de duas bases teóricas que constituem o modelo de análise do estudo: o modelo de a va liação de ma turida de em gestão de riscos do TCU e a teoria institucional em sua vertente sociológica. O trabalho baseou-se em: levantamentos bibliográficos e documentais; questionários; entrevista s e ana lise de conteúdo. Ta is ferra mentas possibilitara m o exame e a apresentação do grau de maturidade (TCU) e do estágio de institucionalização (teoria institucional) do processo de gestão de riscos na Câmara Alta, trazendo luz sobre a aproximação teórica sugerida no modelo de análise. Os resultados indicam que o processo de gerenciamento de riscos no Senado Federal encontra se no início da fase de objetificacão, conforme preceitos da teoria institucional, e adentrando o grau de maturidade Intermediário, de acordo com critérios do TCU. Quanto ao modelo de analise, os dados empíricos não permitiram extrair conclusões sobre sua validade, mas parecem sugerir que a associação entre as duas teorias e possível, uma vez que apontaram, em um mesmo contexto, para graus semelhantes de maturida de e de instituciona lização do processo de gestão de riscos do Sena do. Assim, o estudo a presenta indícios de que um maior grau de maturidade em gestão de riscos segundo os critérios do TCU equivaleria a uma maior institucionalização dessa pratica em uma organização, conforme teoria institucional, suscitando uma reflexão para os estudos sobre o tema.

Palavras-chave: Poder Legislativo. Gestão de riscos. Modelo de Maturidade. Institucionalização. Senado Federal

Nunez, Sarah Albertina Cerqueira. Doze anos de multimídia [manuscrito] : convergência e engajamento público no Portal Senado Notícias, 2020.131 f.

Orientadora: Prof $^{a}$. Dr ${ }^{\mathrm{a}}$. Cristiane Brum Bernardes

Resumo: O objeto deste trabalho é a transformação do site da Agência Senado em um portal de notícias multimídia, nos últimos 12 anos. A relevância de investigar o tema é colocar luz sobre a escolha majoritária pelo modelo jorna lístico de comunica ção nas instituições públicas e sobre as limitações desse ca minho para a promoção do rela ciona mento entre o Legisla tivo e o cidadão. Neste estudo de ca so etnográfico, por meio de entrevistas e de observação participante, principalmente, busca-se mapear que argumentos os profissionais da Secretaria de Comunicação do Senado(Secom) mobilizam sobre a convergência de mídias legislativas - TV, Rádio e Agência Senado - e de formatos de informação no Portal Senado Notícias. Teorias sobre o funcionamento da democra cia justificam e, ao mesmo tempo, iluminam o estudo do papel da comunicação de caráter público para a realização dos valores democráticos. E é desse ecossistema de comunicação que fazem parte as mídias legislativas, como o Portal. À luz de teoria sobre engajamento público, que inclui os a spectos da informação, entendimento, identificação, participação e intervenção como formas de contato entre cidadão e Legislativo, outro objetivo é entender se e em que medida esse grupo profissional associa a transformação do Portal ao incremento do relacionamento do público com o Senado. Dentre as justificativas identificadas e utilizadas pelos profissionais para o início do processo de convergência de mídias no Portal estão o a companhamento de tendências do merca do de not ícias priva do e a integração de informações produzidas pela Secom. Os produtores entendem a convergência como algo necessário e desejável e não a associam apenas com multimidialidade, mas também com gestão da informação, atualização tecnológica e adequação ao consumidor de notícias, estabelecendo relações de diversos níveis entre a produção e a distribuição de conteúdo multimídia e a jornada do engajamento, principalmente nos a spectos da informação, do entendimento e da identifica ção. Ainda que não consensual, a autoima gem desses a tores como produtores de notícias, entretanto, limita a comunicação pública no tange a os fatores da participação e da intervenção.

Palavras-chave: Poder Legislativo. Mídias legislativas. Comunicação pública. Internet. Convergência . Engajamento público.

Silva, Ronaldo Quintanilha da. Accountability horizontal: a fiscalização parlamentar exercida pela Câmara dos Deputados na 55 ${ }^{\mathrm{a}}$ Legislatura, 2020.183 f.

Orientador: Prof. Dr. João Luiz Pereira Marciano

Resumo: Examina como se desenvolveu a fiscalização parlamentar (accountability horizontal) pela Câmara dos Deputados (CD) sobre os atos do Poder Executivo durante a 55 Legislatura (de 2 de fevereiro 
de 2015 a 31 de janeiro de 2019), quando o cargo de presidente da República foi ocupado por dois incumbentes. Neste estudo de caso, o objetivo é verificar o sujeito, o objeto e a amplitude do controle parlamentar, a partir de seis tipos de proposições, denominadas, neste trabalho, de Instrumentos de Fiscalização e Controle (IFC), são eles o requerimento de audiência pública (REQ), o requerimento de convocação de autoridade (RCA), o requerimento de informação (RIC), a proposta de fiscalização e controle (PFC), o projeto de decreto legislativo (PDC) e a solicitação de informação ao TCU (SIT). A explicação dos fenômenos fundamenta-se na teoria da escolha racional e no novo institucionalismo, em sua s vertentes distributivista, informa cionale partidária. As hipóteses delinea das verifica ra m se a a tividade de controle não é relevante, em compa ração à inicia tivas legislativas; se a a tivida de de controle cabe apenas a os deputados de Oposição; se o volume é influenciado pelo ciclo eleitoral e altera -se a partir de eventos externos e, por fim, se as áreas temáticas fiscalizadas são as que reúnem maio res investimentos e se o controle é de abrangência local. A metodologia ba seou-se em análises quantitativas e qualitativas, a partir da base de dados, contendo os instrumentos de fiscalização. Também se adaptaram os modelos utilizados por Lemos (2005), Amorim Neto e Santos (2003) e Raposo (2015). Conclui-se pela existência da fiscalização e controle, porém em patamares abaixo de dez por cento quando comparado à função legiferante. Além disso, verificou-se que ela surge tanto da Base quanto da Oposição, mas que a depender da posição do partido no arranjo institucional ela intensifica ou diminui. Na sequência, encontrou-se influência do ciclo eleitoral na atividade de fiscalização e controle, bem como indícios de que os eventos externos seleciona dos impulsiona ram a lguns instrumentos fiscaliza tórios e outros não. Ao comparar as duas gestões presidencia is, evidenciou-se que os atos e as escolhas da gestão da presidente Dilma Rousseff foram submetidos a mais controle parla mentar do que os do presidente Temer, em função da gestão da coa lizão e do ciclo eleitoral. Por fim, não há evidências de que os deputados são norteados pelo critério de a locação de recursos financeiros para mover ações de controle. Nesse contexto, a Administração Pública concentra mais de vinte por cento do esforço fiscaliza tório e a fiscalização tem cunho nacionale setorial na maioria dos casos. O Instrumento de Fiscalização e Controle preferido dos deputados é o requerimento de informação, seguido pelos requerimentos de audiências, sendo as com issões permanentes as protagonistas das ações.

Palavras-chave: Poder Legislativo. Câmara dos Deputados. Processo legislativo. Função de fiscalização. Controle. Accountability.

Sousa, Sandra Amaralde. Participação política nas mídias sociais: uma análise dos comentários sobre a reforma da previdência nas páginas dos deputados mais influentes do Facebook, 2020.99f.

Orientadora: Prof ${ }^{a}$ Dr $^{a}$. Cristiane Brum Bernardes

Resumo: A pesquisa ana lisa qualita tivamente como ocorre o engajamento público nas pá gina s do Fa cebook dos 10 deputa dos federa is ma is influentes nas redes. Para isso, o estudo a presenta uma análise de conteúdo de postagens e dos comentários recebidos no Facebook por esses parlamentares referentes à discussão e à votação da Proposta de Emenda à Constituição da Reforma da Previdência, realizada em 2019 na Câmara dos Deputa dos. Como estudo de ca so, são a na lisa das, a dicionalmente, as respostas a os comentários de dois dos dez deputados elencados. A pesquisa classifica tanto os tipos de postagens dos deputados, quanto os comentários dessa s postagens, fazendo um coteja mento deles e identificando as diferentes experiências de engajamento público presentes nesse diálogo, conforme as etapas propostas por Leston-Bandeira (2014). Conclui-se que o engajamento de usuários do Facebook no debate sobre a Reforma da Previdência ocorreu, prioritariamente, sob a forma de opinião, com a cobrança eleitoral dos parlamentares e prestação de contas deles para os cidadãos.

Palavras-chave: Poder Legislativo. Mídias sociais. Participação política. Facebook. Accountability discursivo.

Vitolo, Nivea Flausino. Interações entre o Legislativo e o Executivo Federal do Brasil na definição de políticas públicas: especificida des das políticas de saúde a presentadas durante os mandatos Lula II e Dilma I, $2020.139 \mathrm{f}$.

Orientador: Prof. Dr. Fábio de Barros Correia Gomes

Resumo: Esta dissertação buscou caracterizar a atuação dos Poderes Executivo e Legislativo durante o segundo manda to do presidente Lula (2007 a 2010) e o primeiro mandato da presidente Dilma (2011 -2014), 
por meio do cálculo das taxas de sucesso e de dominância do Executivo, nas três vias hierárquicas (constitucional, complementar e ordinária), ta nto para a s política em geralcomo para as políticas de saúde, e, no caso específico destas, por meio de um estudo qualitativo de uma amostra das proposições a presentadas no período e da totalidade das proposições convertidas em norma. Para o cálculo das taxas, utilizou-se o método de Gomes (2011), que permitiu a comparabilidade dos dados obtidos nesta pesquisa com os a cha dos desse a utor. Para a análise qualita tiva, a s proposições de saúde foram cla ssifica das, segundo as tipologias: de Wilson (1973) adaptada, com base na distribuição dos custos e benefícios; do GPE Saúde (CARVALHO et al., 2011), que distingue as políticas de saúde em temas funcionais; e a basea da em Mello (2017), que diferencia as políticas distributivas, de acordo com o nível de discricionariedade e com os beneficiários. As taxas de sucesso do Executivo mantiveram-se elevadas na via ordinária, tanto para as políticas em geral como para as políticas de saúde, tendo sido verificadas grandes variações nas demais vias, com indicativos de maior dificuldade do Executivo a partir de Lula II. Já as taxas de dominância relativa às políticas em geral seguiram o padrão de variação inversamente proporcional à via (GOMES, 2011), com tendência de queda no pós-2003 (ALMEIDA, 2018). No caso da solíticas de saúde, tais padrões não foram reproduzidos; todavia, foi constatada participação parlamentar expressiva nas vias ordinária não orçamentária, complementar e constitucional em todo o período a nalisado, em especial no pós-2003. O aprofundamento da análise qualitativa das características das políticas apresentadas nos mandatos Lula II e Dilma I e das que obtiveram aprovação, indicou uma preferência de a mbos os poderes políticos por proposições distributivas. O caráter mais programático das políticas dessa natureza de iniciativa do Executivo e o maior a lcance em termos de beneficiários confirma ra m uma a tuação mais a mpla desse poder, concentrada predominantemente no plenário da Câmara dos Deputados, na direção da concessão de benefícios de interesse nacional. A grande produção de leis simbólicas e de políticas distributivas de alta discricionarieda de pelo Legislativo indicaram uma a tuação mais restrita e particularista por parte desse poder, com locus de aprovação concentrado nas comissões. Tais acha dos não permitem refutar a ocorrência do fenômeno do segredo ineficiente no Brasil, marca do pela divisão de tarefas entre os poderes políticos. A predominância das proposições dos temas da "Gestão" e de "Direitos", nas vias constitucional e complementar, e do tema da "Prevenção", na via ordinária, revelou que a saúde se encontrava, no período estudado, em uma fase contextual de expansão da abrangência do seu arcabouço jurídico, porém com a retoma da recorrente da questão estruturante do financiamento.

Palavras-chave: Poder Legislativo. Políticas de Saúde. Sucesso. Dominância. Conteúdo da Produção Legislativa. Funcionamento dos Poderes Políticos.

Rosa, Tairone Messias. Partidos políticos contra emendas constitucionais [manuscrito] : panorama da mobilização do STF no período de 1988-2017 / Tairone Messias Rosa. -- 2020. 142 f.

Orientador: Prof. Dr. Ricardo de João Braga

Resumo: Esta pesquisa analisa a contestaçãojudicial, por partidos políticos, de emendas à Constituição de 1988. Para avaliar como se configura o fenômeno da impugnação de emendas pelos partidos políticos, a dissertação examina 27 ações diretas de inconstituciona lidade (ADIs), número que corresponde a o universo de acionamentos do STF durante o período de 1988 a 2017. A pesquisa propicia um pan orama empírico inédito sobre a mobilização de legendas contra mudanças constitucionais, contribuindo, assim, para o debate teórico sobre o acionamento das Cortes por atores políticos e o uso da via judicial como estra tégia política. Entre os principais resultados, está a identificação precisa da quantidade e da frequência das impugnações, além do perfil das 13 legendas diferentes que atacaram reformas constitucionais (v.g. espectro ideológico, experiência na competição eleitoral, posição em relação ao governo, grau de representatividade no Legislativo). Os dados obtidos também oferecem um ponto de observação ainda pouco explorado na literatura, que é, precisamente, o mapeamento das emendas constitucionais mais atacadas pelos partidos brasileiros ao longo de um período de quase trinta anos. Nesse ponto, a pesquisa revelou que apenas $14 \%$ do total de emendas editadas pelo Congresso Nacional sofreu ataques. Outro aspecto abordado e igualmente relevante diz respeito ao conhecimento sobre quais os temas modificados na Constituição de 1988 que mais incitaram os atores partidários a recorrer à jurisdição do STF.

Palavras-chave: Poder Legislativo. Partidos Políticos. Judicia lização da Política. Impugnação de emendas constitucionais. Ação Direta de Inconstitucionalidade.

Ferreira. Vinícius Augusto Sacramento. Geografia política do voto: uma análise dos padrões de votação nas eleições para deputado federal de 2014 à $2018,2020.95 \mathrm{f}$. 
Orientador: Prof. Dr. Ricardo Chaves de Rezende Martins

Resumo: Os estudos de geografia eleitoral, por meio da análise do perfil de votação dos candidatos em distritos eleitorais, formais e informais, são importantes instrumentos para a compreensão do sistema político, possibilitando, inclusive, entendimento mais completo sobre o comportam ento dos agentes e partidos políticos, especialmente na arena parla mentar. O presente trabalho a nalisou os padrões de votação nas eleições para Deputado Federalde 2014 e 2018 e comparou os resulta dos com aqueles encontra dos nos estudos de Carvalho (2003) para os pleitos de 1994 e 1998. A pesquisa a dotou predominantemente a análise quantitativa. A partir dos da dos da seleições disponibiliza dos pelo TSE, combina dos com dados geográficos e de IDH, foram geradas informações no mesmo formato do estudo de Carvalho (2003). Os resultados mostraram que ocorreram mudanças em relação a vinte anos atrás e que as diferenças entre dois pleitos consecutivos ficaram mais acentuadas. Os municípios, notadamente os maiores, se mostraram mais competitivos. Quanto ao perfil dos deputados eleitos, o perfil concentrado seguiu tendência de diminuição e a dominância passou a variar muito mais entre dois pleitos seguidos. Usando-se a tipologia que combina essas duas dimensões, notou-se que o perfil concentrado e dominante se tornou a inda mais raro, enquanto o perfil fragmentado e não dominante consolidou-se como o mais comum entre os deputados eleitos. As predições da fragmentação e da dominância feitas atra vés das variáveis tradicionais tornaram -se menos explicativas. Quando se estudou o perfil dos deputados por meio da dicotomia ca pital/interior, os resultados não alteraram a tendência de vinte anos atrás, com partidos mais ideológicos se destacando mais nas capitais e grandes cidades. Ainda que os resultados obtidos não possam ser extrapolados para inferir resultados futuros, o trabalho se mostra relevante por disponibilizar dados mais recentes sobre a geografia política do voto, podendo contribuir para a compreensão de mudanças no cenário político brasileiro, como também para subsidiar decisões em diversas áreas relacionadas, como o sistema eleitoral bra sileiro.

Palavras-chave: Votos. Deputados Federais. Concentração. Dispersão. Dominância. Distributivismo. Poder Legislativo.

Freitas, Daniela Gomes de. O cidadão tutelado: a interferência do Poder judiciário na corrida eleitoral brasileira : uma análise empírica da aplicação do artigo $1^{\circ}$, I, g, da Lei complementar 64/90, alterado pela "Lei da Ficha Limpa", 2020. 109f.

Orientador: Prof. Dr. Leonardo Augusto de Andrade Barbosa

Resumo: Embora a busca pela "moralidade pública" seja fundamental, também o debate sobre o a specto prático da sua transformação em bandeira política precisa ser tra vado. Com efeito, a proposta desta pesquisa é investigar o terreno a que foi relegada a matéria de inelegibilidades no Brasil, comparando-o com experiências internacionais. De forma mais analítica, pretende-se decomporo artigo $1^{\circ}$, inciso I, alínea g, da Lei Complementar 64/1990, com nova redação dada pela Lei Complementar 135/2010, conhecida como a "Lei da Ficha Limpa", apenas um entre os diversos mecanismos de inelegibilidade trazidos pela legislação, e questioná-lo frente à atuação dos Tribunais. Ademais, busca-se observar o Poder Judiciário brasileiro, evidenciando a existência de contradições no tratamento da matéria, questionando a Lei Complementar 135/2010 por meio da análise da jurisprudência e de casos concretos selecionados. O presente trabalho volta-se, ainda, a investigar se o eleitor tem sido chamado a justificar suas preferências junto à Justiça Eleitoral à revelia da Constituição Federal de 1988.

Palavras-chave: Poder Legislativo. Poder Judiciário. Inelegibilidade. LC 135/2010. Moralidade. Cidadania.

Carvalheiro Neto, Hernani. A liberdade dos subterrâneos: a bancada comunista e os direitos individuais na Constituinte de 1946, 2020.154 f.

Orientador: Prof. Dr. Leonardo Augusto de Andrade Barbosa

Resumo: O trabalho faz uma análise acerca da produção de efeitos das medidas provisórias que são rejeitadas, tácita ou expressa mente, pelo Congresso Na cional, considerando a ausência da edição de decreto legislativo posterior que regule as relações jurídicas constituídas durante o tempo de sua vigência. Para isso é feito um levantamento de todas as medidas provisórias que foram rejeitadas a partir de 2001, quando a Emenda Constitucionaln. ${ }^{\circ} 32$ estabeleceu que, não editado o decreto legislativo os atos praticados durante 
a vigência das medidas provisórias se conservariam mantidos. Na sequência busca -se verificar casos em que há eficácia prospectiva da medida provisória rejeitada, permitindo intuir que o instrumento que permite a Poder Executivo legislar possui ultratividade.

Palavras-chave: Assembleia Constituinte .Partidos Políticos. Comunismo. História do Direito. História do Brasil. Poder Legislativo.

Teixeira Filho, Sócrates Arantes. Emenda constitucional no 86/2015: impactos das emendas orçamentárias de execução impositiva nas relações entre poder executivo e legislativo da União, 2020. $173 \mathrm{f}$.

Orientador: Prof. Dr. André Rehbein Sathler Guimarães

Resumo: A Emenda Constitucional - EC - no 86/2015 tornou impositiva a execução das emendas parlamentares individuais à Lei de Orçamento Anual - LOA - evitando o uso recorrente do mecanismo de contingenciamento e de liberação de recursos orçamentários pelo Presidente da República como meio de submeter os parla mentares a os seus interesses, a lém de ga rantir maior eficácia na execução dessas emendas. O presente trabalho tem como objetivo a nalisar os efeitos da referida emenda, comparando a execução no período de 2010 a 2014 com o período de 2015 a 2019, buscando identificar em qual medida houve aumento do percentual de execução das despesas com emendas parlamentares individuais, após a EC. Para tanto, trabalhou-se com as diferenças na evolução da execução da s emendas individua is à s Leis Orça mentárias de a cordo com o tipo de parla mentar (deputado ou sena dor), com a situação dos partidos em relação ao govemo (situação, neutro, ou oposição), com o tamanho do partido no Congresso Na cional, com a situação do a utor da emenda (com ou sem mandato) no ano da sua vigência, com a região de origem do autor, com a classificação funcional, com a classificação do tipo de ação orçamentária (atividade, projeto ou operação especial), e com a abrangência espacial da despesa. A justificativa para a pesquisa é o fato de o controle sobre a execução das emendas orçamentárias ser apontado como uma das principais ferramentas disponíveis a o Presidente da República para controlar a agenda legislativa, no âmbito do que se configurou como o presidencialismo de coalizão no Brasil. A pesquisa realizou uma análise qua litativa e quantita tiva da execução das emendas parla mentares individua is à LOA, no sistema SigaBra sil do Senado Federale nos bancos de dados sobre emendas da Consultoria de Orçamentos da Câmara dos Deputados, e concluiu que a EC 86/2015 reduziu a margem de discricionariedade do Poder Executivo em relação à execução das emendas parla mentares individuais, sem eliminá -la por completo, de modo que a decisão sobre o momento da execução das emendas ainda é um instrumento de controle da pauta do Poder Legislativo.

Palavras-chave: Poder Legislativo. Orça mento Público. Emendas. Presidencialismo. Coalizão.

Hofmannn, Rose Mirian. Avaliação do impacto legislativo do projeto de Lei Geral do Licenciamento Ambiental: uma análise do potencial de otimização dos procedimentos com a aplicação das novas regras, $2020.93 \mathrm{f}$.

Orientador: Prof. Dr. Maurício Schneider

Resumo: O licenciamento ambiental brasileiro tem sido alvo de constantes críticas sobre a imprevisibilidade em termos de prazo e escopo, especialmente na primeira fase da avaliação, o licenciamento prévio. Nesse cenário, o Poder Legislativo tem debatido uma série de proposições com o objetivo de desburocratizar o procedimento, tornando-o mais célere, com a promessa de que tal aprimoramento não resultará em fra gilização do mérito das análises técnicas. Na Câmara dos Deputados, a té o finalda $55^{\text {a }}$ legisla tura (2015-2019), tra mita vam vinte e três proposições sobre o tema, sendo o Projeto de Lei (PL) no 3.729, de 2004, o principal. Este trabalho teve como objetivo promover uma avaliação do potencial de otimização dos procedimentos com a aplicação das novas regras, em debate no âmbito dos projetos em trâmite no legislativo. A metodologia adotada consiste no cotejo das normas atuais com as propostas de abordagem legislativa no âmbito do Projeto de Lei Geral do Licenciamento Ambiental, verificando-se em cada etapa do processo qual é o nível de aprimoramento. A análise restringiu-se aos normativos a plicá veis a os processos conduzidos na esfera federal, licenciados pelo Instituto Brasileiro do Meio Ambiente e dos Recursos Naturais Renováveis (Ibama). Os resultados contribuíram para melhor delimitar o problema a ser resolvido pelo projeto de lei em relação a o consumo de tempo por ca da etapa do processo, indicando a necessidade de maior a tenção à quelas que antecedem o a ceite dos estudos pelo órgão 
a mbiental para análise de mérito. A pesquisa ta mbém mapeou dispositivos estruturantes do projeto de lei que podem aprimoraro instrumento em relaçãoà eficiência e efetividade. Por fim verificou-se que o Projeto de Lei Geral do Licenciamento Ambientalinova pouco, mas consolida uma série de procedimentos esparsos em um único ato, favorecendo o entendimento do tema e a formação de jurisprudência no decorrer do tempo. A ideia de otimização, embora presente em todos os debates, tem sido deixada preponderantemente a cargo de futura regula mentação da lei, em caso de aprovação do projeto. Nessa situação estão as etapas de enqua dra mento e tria gem, na s qua is são definidas quais a tivida des e empreendimentos serão submetidos a o licenciamento e com qualnível de rigor. Por fim, destaca -se a relevância da a provação de uma lei sobre a matéria, principalmente para esclarecer e consolidar conceitos e papéis que, embora presentes há muito tempo no ordenamento jurídico, se mostram bastante controversos no debate legislativo.

Palavras-chave: Ava liação do impacto legislativo. Licenciamento a mbiental. Desburocratização. Gestão pública.

Castro, Tarciane Silva de Araújo. A atenção domiciliar (home care) no âmbito do plano de saúde do Senado Federal: isomorfismo e institucionalização, 2020.145f.

\section{Orientador: Prof. Dr. Valério Augusto Soares de Medeiros}

Resumo: A pesquisa consiste em uma análise da assistência domiciliar (AD) oferecida pela rede credencia da do plano de saúde do Sena do Federal, denominado Sistema Integra do de Saúde (SIS). Discute se o grau de institucionalização dessa assistência à luz do neoinstitucionalismo e a existência de isomorfismo institucional, a partir de duas questões de pesquisa: 1) Em qual está gio está o processo de institucionalização da assistência domiciliar - home care do Senado Federal?; e 2) Há evidências de isomorfismo institucional nesse processo? A monografia é qualitativa e compreende um estudo de caso com característica explora tória e descritiva. Para identificar a ocorrência e o grau de institucionalização da $\mathrm{AD}$ do Senado Federal adota-se, a partir da perspectiva do institucionalismo sociológico, a modela gem de Tolbert e Zucker (1998). Para tanto, são rea lizadas entrevistas com os gestores do SIS com a fina lidade de investigar os está gios de instituciona lização (habitua lização, objetificação e sedimentação), compostos por forças causais e características com poder de explicação para o processo de institucionalização das estruturas organizacionais. Relacionam, durante a análise dos documentos e das entrevistas, a s forças causais e características evidenciadas em cada fase do processo de institucionalização. Os resultados obtidos apontam que a $\mathrm{AD}$ do Senado Federal possui forças causais e características das três fases da instituciona lização, demonstrando que, mesmo com a inexistência de obrigação, por parte do gestor do SIS, de oferecê-la, essa assistência se encontra em uma condição mais aproximada ao estágio da institucionalização total ou sedimentação, que é marcada pelo apoio na continuidade da estrutura e pela consolidação da AD dentro do Sena do Federal. Adicionalmente, percebeu -se que há a presença de variá veis semelhantes, cotejando-se os modos de oferta de AD do SIS e do SUS, caracterizando predominantemente a presença do isomorfismo coercitivo.

Palavras-chave: Poder Legislativo. Home Care. Assistência Domiciliar. Institucionalismo Sociológico.

Cavalhero, Myriam Violeta. A casa das 13 mulheres: o discurso das senadoras sobre o impedimento de Dilma Rouseff, 2020.134f.

Orientador: Prof. Antonio Teixeira De Barros

Resumo: Este estudo objetivou a na lisar como se comportaram discursivamente, durante o julga mento do impeachment de Dilma Rousseff, as mulheres que compunham o Sena do Federal, instância responsável por julgar o impedimento dos presidentes da República. Para isso, buscou-se identificar, nas manifestações ora is no a mbiente do plenário, na quele período, indícios que permitissem encontrar a condução dos sentidos para reforçar a existência da desigualdade entre homens e mulheres, sobretudo na política. Outra premissa era que os pronuncia mentos dessas mulheres poderiam sercapazes de convencer, a té o ponto de influenciar, para alterar a decisão dos outros senadores no resultado do processo. Para tanto, utilizou -se a metodologia das escolas de Análise de Discurso (AD), de linha francesa e da Análise Crítica do Discurso (ACD). As 13 mulheres que julgaram Dilma Rousseff foram distribuídas em espectros ideológicos com vistas a observar se os discursos proferidos esta va m coerentes com o posiciona mento político. Ta mbém se investigou o lugar de fala, as estratégias retóricas e as estruturas dos pronunciamentos dessas parlamentares que, dadas as 
condições de acesso à arena política, por si só já podem ser consideradas exceção num ambiente tradicionalmente masculino. A escassez de estudos dos discursos construídos durante o processo de impeachment, sobretudo das mulheres detentoras de mandato, justifica a presente pesquisa. Outro mérito de investigações desta natureza é que, ao derramar luz sobre como elas retratavam, por meio de suas manifestações orais, a maneira como viam a si mesmas, as outras mulheres e, principalmente, a única mulher a chegar a cargo de presidente da República, é possível contribuir na compreensão de como se construíram identidades discursivas femininas na prática específica do impeachment. Além de observara existência de discursos inerentes aos espectros ideológicos e aos lugares de fala, encontrou-se que a repetição, como estratégia retórica, não surtiu efeitos e que era possível uma disputa discursiva pela presunção da verdade. Conclui-se, pelas a nálises, que o posicionamento político e discursivo nem sempre coincidiu com o espectro ideológico e que, a depender desse espectro, o discurso da desigualdade entre homens e mulheres, principalmente na arena política, foi valorizad o ou ignorado pelas senadoras.

Palavras-chave: Poder Legislativo. Análise de Discurso. Impeachment. Política e gênero. Desigualdade política.

Teles, Fausto Barros de Sá. A reforma do marco legal do petróleo sob duas visões de política energética, 2020.113f.

Orientador: Prof. Dr. Mauricio Schneider

Resumo: Entre 2016 e 2018, o governo Temer realizou uma reforma no marco legal brasileiro de exploração e produção de petróleo e gás natural, que foi objeto de intensos debates no Congresso Nacional. Este trabalho analisa essa s modificações e sua relação com os resultados dos leilões de áreas do pré-sal sob o regime de partilha de produção, tendo em conta os argumentos de defensores e opositores da reforma, com vistas a contribuir com evidências para futuras deliberações. As modificações e argumentos apresentados foram obtidos diretamente na legislação e em documentos produzidos pelas comissões das duas Casas do Congresso Nacional, e examinados a partir de referencial teórico sobre ideologias políticas, política industrial e política energética. Dessa análise, resultam critérios para a va liação do desempenho da reforma, o que é feito utilizando dados dos resultados dos leilões e contribuições de outros estudos sobre o tema. Embora a legislação não seja o único fator influenciando o mercado de óleo e gás, o que limita as possibilidades de análise sobre o impacto da reforma, as evidências reunidas sugerem que essa política pública contribuiu para o alcance de resultados superiores nos leilões, com efeitos adversos pouco relevantes. Ao final, explora-se propostas de alterações futura s no marco legal em um cenário de transição energética acelerada e de preços baixos de petróleo.

Palavras-chave: Política pública. Energia. Óleo e gás. Pré-sal. Partilha de produção. Poder Legislativo.

Carvalho, Ginny Carla Morais de. Plenários a o vivo nos parlamentos americanos: transparência, publicidade e estímulo à accountability, 2020. $219 \mathrm{f}$.

Orientadores: Prof. Dr. Antônio Teixeira de Barrose Profa. Dra. Cláudia Regina Fonseca Lemos

Resumo: O estudo tem o objetivo investigar em que medida os parlamentos nacionais dos países do continente americano utilizam as transmissões ao vivo por vídeo das sessões plenárias como forma de transparência, publicidade e estímulo à a ccountability. Trata -se de uma pesquisa inédita, que propõe suprir uma lacuna comparativa e analítica nos estudos da área, considerando o continente americano como um todo, com seus 35 países independentes e respectivas 55 casas legislativas. O panorama foi traçado sob a ótica dos estudos sobre transparência, publicidade e accountability e levou em consideração informações coletadas por meio de observação sistemática direta das sessões plenárias e de questionários eletrônicos respondidos pelos próprios legislativos. Os resultados mostram que não foi verificada transmissão ao vivo em vídeo das sessões plenárias em a penas dois países do continente: Haiti e Belize. Nos demais, o público tem ao menos uma forma de assistir em tempo real as discussões e decisões da arena mais importante do Poder Legislativo. O meio predominante de transmissão a o vivo em vídeo é a internet, mas os parlamentos ainda não a proveita mo potencial intera tivo da tecnologia. Há multiplicida de quanto a o formato e conteúdo oferecidos nas transmissões. Foram feitas classificações e análises de variáveis técnica s e informativas, sempre tendo como foco o que é coloca do à disposição do cidadão. Por isso, foi dado destaque aos países que utilizam a mediação jornalística para permitir maior inteligibilidade: 24 casas parlamentares incluem 
jorna listas nas transmissões a o vivo, a maioria antes e/ou depois do período regimentalda sessão; oito delas inserem explicações orais também durante o evento, nos intervalos entre os discursos parlamentares, permitindo que o público seja informado sobre o ponto em questão e possíveis consequências. A investigação ainda identificou que a decisão do Legislativo de oferecer mais explicações em tempo real na transmissão em vídeo vem acompanhada de outras ações de divulgação da sessão plenária em diferentes formatos e meios. Conforme se ampliam as explicações na transmissão ao vivo, foi constatada uma alteração no perfil dos países no que diz respeito a variáveis políticas e estruturais, verificando-se, por exemplo, maior incidência em países presidencialistas, com democracia falha e representantes eleitos por meio de sistema proporcional. Conclui-se que a transmissão ao vivo traz transparência e publicidade aos atos parlamentares, mas em graus diferenciados. A maior visibilidade proporciona da pela transmissão ao vivo em vídeo das sessões plenárias incentiva a accountability parlamentare atua para o forta lecimento da representação e da democracia, embora também seja verifica da em países considera dos a utoritários, onde o procedimento pode ser instrumento para tra vestir de democracia um processo político que, na verdade, é controlado. Por fim, a ponta-se o desafio de qualificar as informações das transmissões a o vivo das sessões plenárias para ampliaro entendimento, promover maior interatividade e aumentaro grau de engajamento público.

Palavras-chave: Transmissão ao vivo. Televisão legislativa. Mídias legislativas. Plenário.

Mazzola Junior, Osvaldo. Identificando o capital humano no setor público: uma análise sistemática e comparada com as práticas de avaliação educacional na Câmara dos Deputados, $2020.178 \mathrm{f}$.

\section{Orientador: Prof. Dr. Roberto Campos da Rocha Miranda}

Resumo: Esta pesquisa foi elaborada com o objetivo geralde identificar indicadores de capital humano em organizações públicas brasileiras, conceituados pela produção acadêmica no período de 2015 a 2019 , passíveis de análise a partir das práticas de a valiação educacional corporativa da Câmara dos Deputados. O estudo realça a importância do significa do estra tégico do ca pital huma no pa ra as orga nizações no mundo contemporâneo, o qual, desde o final do século passado, experimenta a era da informação ou da sociedade do conhecimento. Tempos em que informações e conhecimentos são produzidos em escalas nunca vistas, gerando impactos significativos no ambiente privado e público de negócios. Razões pelas quais conhecer as atuais competências dos servidores e desenvolver as novas necessárias é fator crítico para fazer mais eficiente e moderna a administração pública. No trabalho adotou-se metodologia analítico-qualita tiva, para explorar e descrever o objeto de pesquisa, mediante o uso de revisão sistemática de literatura e estudo comparado. Realizou-se uma revisão de escopo sobre modelos de ca pital humano e uma análise documental nos registros das avaliações educacionais conduzidas pelo Centro de Formação, Treinamento e Aperfeiçoamento (Cefor) da Câmara dos Deputados, de maneira a proporcionar uma comparação de elementos dessas práticas a va liativas com indica dores da quele capital aplicá veis a orga nizações públicas no Brasil. Na revisão de escopo, foram identificados 268 artigos acadêmicos nas bases de dados dos sistemas de busca de bibliografia da Câmara dos Deputados, do ProQuest Central e da Elsevier ScienceDirect. Após triagem e seleção, com fundamento em critérios de elegibilidade protocolados, 32 desses estudos tiveram mapeados os conceitos, as características, os indicadores e os métodos de mensuração de capital humano. A análise documental dos modelos de avaliação educacional do Cefor descobriu 23 elementos relacioná veis a indicadores de ca pitalhumano consoante a academia. O cotejo de a mbos os conjuntos de dados (indicadores e elementos de avaliação) revelou que as atuais formas de a va liação de ações educativas na Câmara possibilitam, embora incompletamente, a nalisar nove instâncias de indicadores de capital humano, nas dimensões cultura e clima organizacionais, compartilhamento e comunicação, e competências. Verificou-se que esses processos avaliativos não foram elaborados para especifica mente medir o ca pital huma no, a ssim como em parte con siderá vel ca recem de documentação. Os resultados mostraram ser viável utilizar a valiações educacionais como uma ferramenta para monitorar e a valiar o capital humano em organizações públicas brasileiras, neste caso utilizando os parâmetros dos modelos avaliativos da Câmara dos Deputados. Para organizações do conhecimento, feito a Câmara, (re)conhecer o valor das pessoas que aplicam seu capital humano no trabalho é extremamente relevante e crítico para o sucesso da Instituição. Sobretudo quando atualmente se avizinha uma reforma, no âmbito dessa Casa Parlamentar, que busca novos paradigmas para o serviço público, baseados em avaliação de desempenho de servidores, eficiência administrativa, economicida de e transparência.

Palavras-chave: Poder Legislativo. Gestão estratégica. Educação legislativa. Capital humano. Ava liação educacional. Revisão de escopo. 
Correa, Roberto Rondon. FIRE ALARM OU POLICE PATROL? Análise da atuação parlamentar da Comissão de Fiscalização Financeira e Controle da Câmara dos Deputados no período da $55^{\mathrm{a}}$ Legislatura (2015-2019) à luz de uma abordagem teórica sobre fiscalização congressual, 2020.99 f.

Orientador: Prof. Dr. João Luiz Pereira Marciano

Resumo: A fiscalização e controle das estruturas e atos governamentais é papel essencial do Poder Legislativo, sendo que, nas últimas décadas, em que o Brasil retornou à normalidade democrática, tornouse, novamente, ferramenta fundamental a o pleno exercício da democra cia. Em 2003 foi cria da a Comissão de Fiscalização Financeira e Controle (CFFC), justamente com o objetivo de estruturar essa fiscalização por parte da Câmara dos Deputados (CD). A crescente participação da sociedade, por meio de organizações não governamentais, na fiscalização da coisa pública, tem tornado a necessidade de pronta resposta pelo Poder Legislativo ainda maior. Ao longo dos últimos anos o volume de fiscalização cresceu e se diversificou. $\mathrm{O}$ presente estudo buscou analisar, no período da $55^{\mathrm{a}}$ Legislatura, o principal instrumento de fiscalização da CFFC e da Câmara dos Deputados, a Proposta de Fiscalização e Controle (PFC), na visão comparativa de dois modelos de fiscalização congressual: fire alarm, que se consubstancia num processo reativo de fiscalização, e police patrol, que está ligado a um processo planeja do e constante de fiscalizara administração pública. O quadro teórico para análise dos dois modelos envolveu as teorias da accountability, da Agência e distributiva, ligada ao princípio da Conexão Eleitoral, em que se pode compreender melhor os comportamentos e motivações de quem delega a fiscalização (principal) e quem a executa (agente) no âmbito da arena legislativa. A metodologia compreendeu, ainda, análise quantitativa das PFCs no período de foco. Como resultado, observou-se um maior enqua dramento das PFCs no modelo fire alarm. Identificou-se, também, que as características das vertentes fire alarm e police patrol não são estanques, e se interrelacionam entre os modelos. Os dados apontam para uma possível insuficiência do modelo de McCubbins e Schwartz (1984) para explicar o enqua dramento da fisca liza ção parla mentar, sendo que esses dados sina liza m para a possibilida de de se desenvolver um modelo explica tivo baseado nas teorias de organização do comportamento parla mentar(distributiva, informacionale partidária).

Palavras-chave: Fire alarm. Police patrol. Accountability. Conexão eleitoral. Teoria da a gência. Poder Legislativo.

Moor, Francine. Mulheres e lobby no Brasil [manuscrito]: como elas jogam o jogo dos homens no Congresso Nacional, 2020.83f.

Orientador: Prof ${ }^{\mathrm{a}} \mathrm{Dr}^{\mathrm{a}}$. Giovana Dal Bianco Perlin

Resumo: O contexto de atuação profissional do lobby, a política, é um espaço caracterizado pela sub representação feminina. Assim sendo, a forma como as decisões são tomadas e as negociações são realizadas reproduz padrões de comportamento e de cultura tradicionalmente masculinos. Analisar a atuação das mulheres em atividade de lobby no Congresso Nacional, descrevendo essa atividade e identificando os impactos de gênero na atuação profissional configura o principal objetivo deste estudo. Para alcançar esse objetivo esta pesquisa coletou dados quantitativos e qualitativos de diferentes fontes sobre os profissionais de lobby no Brasil e buscou identificar, por meio da análise da percepçãode mulheres e homens profissionais da área, como gênero repercute na sua prática profissional e na sua carreira. $\mathrm{O}$ estudo mostra que as principais barreiras experimentadas pelas mulheres na atividade de lobby são: persistência de dilemas relativos à interação família -trabalho; o sexo como variável explicativa para as diferenças remunera tórias; a old boy's network, ou "o clube de homens" representando uma barreira para a a scensão de mulheres na carreira e para o sucesso profissional; o assédio sexualexplícito e velado como barreira importante e transversal, impactando negativamente em vários processos da atividade laborale também no desenvolvimento profissional; e um maior engajamento das mulheres em atividades técnicas do que em atividades de articulação política como estratégia para lidar com as barreiras citadas.

Palavras-chave: Poder Legislativo. Lobby. Características de gênero. Estereótipos. Equidade de gênero. Sub-representação da mulher.

Silva, Dhyego Marcus Cruz e. Mudança institucional no Congresso Nacional: uma análise a partir da judicialização do veto dos royalties do petróleo, 2020.204f. 
Orientador: Prof. Dr. Ricardo de João Braga

Resumo: O a mbiente político é estruturado por uma dinâmica institucional caracterizada por constantes tensões e conflitos decorrentes da relação entre atores e instituições. Esses atores exploram ativamente as "regras do jogo", como as atinentes ao processo legislativo. No Congresso Nacional (CN) há uma multiplicidade dessas regras, constitucionais e regimentais, que regem os trabalhos e estruturam comportamentos. Embora majoritariamente formais e escritas, elas geram disputas em torno de seu significado, interpretação e forma de aplicação na prática, durante a tra mitação de proposições legislativas. Parte desses conflitos não encontra solução na arena política e acaba migrando para o Poder Judiciário, por meio da judicialização do processo legislativo, fenômeno cada vez mais crescente. Um dos instrumentos utilizados é o mandado de segurança (MS), pelo qual os parlamentares, como a utênticos partícipes desse processo legiferante, ingressam no Supremo Tribunal Federal (STF), arguindo, em muitos casos, questionamentos em torno dessas regras. Nesse contexto, o objetivo do estudo foi verificar como decisões do STF, nessas ações, provocam ou contribuem com mudanças institucionais no CN, transformando-o. Para tanto, valeu-se do método de estudo de caso, cuja unidade de análise foi o MS n ${ }^{\circ} 31.816$, relativo ao veto presidencial a posto a o Projeto de Lei de redistribuição dos royalties do petróleo. A abordagem da pesquisa não foi a na lisar a fundamentação jurídica ou doutrinária das decisões judiciais, tampouco traçar limites da atuação do STF no Poder Legislativo. A pesquisa utilizou-se de um olhar institucionalista, focado na mudança institucional, relacionando de forma inovadora esse complexo fenômeno com o da judicia lização do processo legislativo. Esse MS, que teve grande repercussão política e importantes desdobramentos no $\mathrm{CN}$, revelou um quadro institucional de contestação das regras formais de deliberação dos vetos presidenciais. Verificou-se que o conflito quanto a essas regras não se iniciou com a judicialização, que teve um papel relevante no processo de mudança, porém secundário. Concluiu-se que a mudança institucional no $\mathrm{CN}$ no caso em a nálise não se realizou de forma abrupta, decorrente de fatores externos, como sustenta grande parte das tradicionais abordagens neoinstitucionalistas. Ela foi gradual e transformadora, identificada a partir de modelo teórico específico. Além disso, se processou de forma endógena, ao longo dos anos, pelo acúmulo de inúmeros conflitos protagonizados pelos próprios parla mentares, que desafia vam as instituições em questão. E resultou em uma alteração da práxis decisória a dotada há décadas e uma reconfiguração do poder a tribuído à Mesa do CN.

Palavras-chave: Poder Legislativo. Mudança Institucional. Judicialização. Processo Legislativo. MS $\mathrm{n}^{\circ}$ 31.816. Royalties do Petróleo.

Correia, Fernando Tavares. $O$ exame de adequação e compatibilidade orçamentária e financeira na Câmara dos Deputados na 55ª legislatura: uma abordagem informacional, 2020.158f.

\section{Orientador: Prof. Dr. João Luiz Pereira Marciano}

Resumo: Esta dissertação trata do exame de adequação e compatibilidade orçamentária e finance ira das proposições legislativas no âmbito da Câmara dos Deputados. O objetivo proposto foi entender como a Câmara dos Deputados adquiriu informação para tomada de decisão acerca desse tema durante a $55^{\mathrm{a}}$ legislatura, com abordagem descritiva e exploratória e amparo no modelo informacional. Verificou-se que o despacho inicial do Presidente da Câmara dos Deputados (PCD), que define os colegiados a que cada proposição é submetida, é uma decisão técnica. Embora a escolha dos presidentes das comissões permanentes seja partidária, a escolha dos relatores e presidência nos colegia dos temporários tem motivação informacional e partidária. Identificou-se na Comissão de Finanças e Tributação (CFT) e nas comissões mistas que analisam as medidas provisórias (MPV) a figura da consultoria de orçamento como um a tor informa cional. Ta mbém se encontrou evidência de que há delegação legislativa na sproposições de autoria externa que tra mitaram na CFT e nas MPV ana lisa das pela s comissões mistas, evidência não observada em Plenário. Os colegiados com poder terminativo sobre a adequação e compatibilidade orçamentária e financeira (CFT e comissões especia is) tiveram suas opiniões mantidas pelo Plenário, o que evidencia que a decisão desses colegiados representa a vontade do legislador mediano do Plenário. Ao final, foram apresentadas sugestões de melhoria para o processo informacional sobre a adequação orçamentária e financeira e sugestões de estudos futuros.

Palavras-chave: Adequação e Compatibilidade Orçamentária e Financeira. Modelo Informacional. Comissão de Finanças e Tributação. Consultoria de Orçamento e Fiscalização Financeira. Poder Legislativo. 
Mesquita, Rômulo de Sousa. Parcerias público-privadas em casas legislativas: possibilidades e desafios, $2020.153 \mathrm{f}$.

Orientador: Prof. Dr. Nelson Gomes dos Santos Filho

Resumo: Este trabalho tem o objetivo de verificar qua is são as possibilida des e os desafios para a rea lização de Parceria Público-Privada (PPP) em uma Casa Legislativa. A pesquisa não tem precedente e po de auxiliar em futuras modelagens de PPPs nesse âmbito de Poder. Foi desenvolvida como estudo de caso múltiplo, considerando as experiências inacabadas da Câmara dos Deputados e da Câmara Municipal da cidade do Recife. Na Câmara dos Deputados, a experiência percorreu quase toda a etapa pré-contratual de estruturação de uma PPP. A Lei $\mathrm{n}^{\circ}$ 13.137/2015, incluiu as Casas do Poder Legislativo no rol dos autoriza dos a estruturarem PPP, o que impulsionou a elaboração de normativos internos e regula mentação do processo de estruturação do projeto na CD. A instituição ofereceu ca pacitação inicialem gestão de PPP para o corpo técnico e constituiu a Comissão Especial para a elaboração e a publicação do edital do PMI, com o projeto arquitetônico e a metodologia para o cá lculo do preço público compara do (PPC), e a va liação das propostas, que seriam recebidas. O projeto avançou até o recebimento de proposta de uma das cinco empresas autorizadas para desenvolverem os estudos. No caso da Câmara Municipal do Recife, a experiência foi mais incipiente. Seu principal legado foi a constituição do Fundo Gestor Especial, com o objetivo específico para a construção da sede da Ca sa Legislativa. Apesar de não terem a vançado nas fases da etapa pré-contratual de PPP, a Instituição tem se preparado financeiramente com a capitalização do fundo, o que possibilita a utilização desse instituto no futuro. Mesmo sem a conclusão dos projetos, há espaço para a plicação desse instituto nos diversos níveis do Poder Legisla tivo bra sileiro.

Palavras-chave: Parceria Público-Privada. Concessões administrativas. Modelagem de PPP no Poder Legislativo. 